\title{
Oficina Pedagógica de Mapas Mentais no Ensino Médio: percepção dos sentimentos e valores atribuídos ao lugar
}

\author{
Pedagogical Workshop from the Mental Maps in High School: Perception of Feelings \\ Assigned to Places
}

\section{Taller Pedagógico de Mapas Mentales en la Enseñanza Media: Percepción de los Sentimientos y Valores Atribuidos al Lugar}

\author{
Margarida de Cássia Campos ${ }^{1}$ \\ Thais Gaffo Vacari ${ }^{2}$
}

\begin{abstract}
RESUMO: O presente texto tem como objetivo analisar como os estudantes do ensino médio de escolas do campo no município de Londrina percebem as espacialidades de seu lugar de vivência a partir da interpretação de oito mapas mentais, tendo como aporte teórico as concepções da Geografia Humanista. Como procedimento metodológico utilizou-se a leitura e os fichamentos de textos, organização e planejamento da oficina pedagógica e aplicação da mesma. Por fim, conclui-se que os educandos atribuem sentimentos e valores ao lugar de vivência na medida em que interagem com o mesmo e criam relações afetivas com seus pares.
\end{abstract}

PALAVRAS-CHAVE: Ensino de Geografia. Mapas mentais. Ensino médio.

ABSTRACT: The present text has as its goal to analyze how high-school students from the country schools in Londrina realize specialties of their living areas, from the interpretation of eight mental maps, having as a theoretical approach the conceptions of Human Geography. As its methodological procedure the reading of texts and summaries, the organization and planning of a pedagogical workshop and its applicability were used. Lastly it was concluded that learners assign feelings and values to their living place as they interact with it and build sentimental relationships with their pairs.

KEYWORDS: Geography teaching. Mental maps. High school.

RESUMEN: El presente texto tiene por objetivo analizar cómo los estudiantes de la enseñanza media de las escuelas rurales en la ciudad de Londrina notan las espacialidades de su sitio de vivencia desde la interpretación de ocho mapas mentales, teniendo como contribución teórica las concepciones de la Geografía Humanista. Como procedimiento metodológico se ha utilizado la lectura y registros de textos, organización y planificación del taller pedagógico y su aplicación. Por último, se ha concluido que los educandos atribuyen sentimientos y valores al lugar de vivencia a medida que interactúan con él y crean relaciones afectivas con sus pares.

PALABRAS CLAVES: Enseñanza de Geografía. Mapas mentales. Enseñanza media.

\footnotetext{
${ }^{1}$ Universidade Estadual de Londrina, Campus Universitário. CEP: 86.051-990, Londrina - Paraná. Caixa Postal: 6001, Londrina - Paraná: mcassiacampos@hotmail.com.

2 Universidade Estadual de Londrina Campus Universitário. CEP: 86.051-990, Londrina - Paraná. Caixa Postal: 6001, Londrina - Paraná: thais.gaffo@hotmail.com.
} 


\section{INTRODUÇÃO}

As representações de um determinado lugar são feitas desde o homo sapiens sapiens, que utilizava os recursos naturais para desenhar a paisagem ao seu redor. Tais desenhos propiciaram aos cientistas compreender como era a vida de nossos antepassados e quais suas relações com o espaço vivido.

Entende-se que os mapas mentais não são diferentes, porque são desenhos confeccionados pelos estudantes para expressar suas opiniões, valores e sentimentos para um dado lugar, muitas vezes possibilitando ao professor conhecer suas subjetividades, apreender como adolescentes e jovens atribuem sentimentos e valores aos espaços de vivências e como eles constroem sua identidade no encontro com o lugar.

Tendo como base essa afirmativa, as autoras do presente texto planejaram e aplicaram uma oficina pedagógica, nos meses de maio, junho e julho de 2016 em seis escolas de ensino médio dos distritos de Londrina: Colégio Estadual Maria Helena Davatz, Colégio Estadual de Guaravera, Colégio Estadual Professor Altair Aparecido Carneiro, Colégio Estadual Capitão Euzébio Barbosa de Menezes, Colégio Estadual da Warta e Colégio Estadual de Maravilha.

Esta atividade fez parte do Programa Novos Talentos de Ciências Humanas da Universidade Estadual de Londrina, que teve início em março de 2014 e encerrou suas atividades em setembro de 2016. Um dos objetivos do Programa é aproximar a Universidade da Escola Básica no sentido de torná-las parceiras no processo de formação dos jovens de ensino médio das escolas públicas.

O objetivo da oficina pedagógica era de perceber as vivências dos estudantes, as formas de construção de identidades, representação e atribuições de valores e sentimentos ao espaço vivido, além do pertencimento ou estranhamento para com o mesmo. Ao final das oficinas recolhemos 124 mapas mentais. Parte dos resultados obtidos com as representações (mapas mentais) será debatida no presente texto.

Portanto, o texto que segue apresenta o propósito de compreender como oito estudantes do ensino médio de seis escolas do campo do município de Londrina percebem as espacialidades do seu lugar de vivência, tendo como aporte teórico as concepções da Geografia Humanista. Como procedimento metodológico utilizou-se a leitura e o fichamento de textos, a organização e o planejamento da oficina pedagógica, a aplicação nas escolas e, por último, a compreensão dos mapas. Para análise das representações a metodologia qualitativa foi a escolhida, por permitir uma abordagem mais compreensiva ou interpretativa do cotidiano dos jovens que confeccionaram os mapas. 


\section{OS MAPAS MENTAIS: DISCUSSÕES E RESULTADOS}

O surgimento dos mapas mentais, segundo Landim Neto e Dias (2011), tem relação direta com a Geografia Humanista e da Percepção (correntes do movimento de renovação da Geografia) que valoriza o ser humano, dando importância principalmente aos sentimentos que eles atribuem a um determinado lugar. Para os autores, os mapas mentais podem ter diferentes nomenclaturas, como por exemplo, mapas cognitivos, desenhos mentais e cartas mentais, entretanto: "[...] há de se enfatizar que tais definições e abordagens muitas vezes dialogam entre si de modo a se complementarem" (LANDIM NETO; DIAS, 2011, p. 8), ou seja, mesmo que alguns autores utilizem outros nomes, na maioria das vezes o conceito se refere ao mapa mental.

$\mathrm{Na}$ aplicação da oficina pedagógica primeiramente iniciou-se uma conversa de receptividade com os estudantes, essa aproximação teve como objetivo promover empatia entre pesquisador e os sujeitos da pesquisa. Após o diálogo de aproximação, houve uma discussão questionando-os sobre quais profissionais e/ou pessoas teriam a função de elaborar um mapa. A maioria dos estudantes apontava sempre um profissional especializado (cartógrafos, engenheiros etc). A partir dessas respostas, tentou-se fomentar o diálogo e demonstrar para os mesmos que, a priori, estavam parcialmente certos, mas que nem sempre pessoas especializadas são as únicas que podem confeccionar mapas, e nesta etapa da conversa adentrou-se na discussão de que eles podiam produzir seus próprios mapas.

Após esta etapa discutiu-se a organização espacial de cada lugar (distrito) e das comunidades que os jovens viviam, sempre incentivando os estudantes a falarem sobre 0 seu espaço vivido, neste ínterim o conceito de lugar como espaço de vivência foi introduzido. Por meio destas discussões sempre aparecia a pergunta: O que poderíamos considerar "nosso lugar"? Assim foi possível motivá-los a representar o seu lugar, apresentando elementos que incentivaram a reflexão acerca da comunidade em que vivem. Para Archela, Gratão e Trostdorf (2004) é na representação do lugar que aparecem os valores, a união ou a separação das pessoas, o gostar ou o não gostar e as representações do imaginário.

Utilizou-se para a confecção dos mapas uma folha de papel A3, lápis, régua e borracha. E sempre quando eles perguntavam pode colocar "isso" ou "aquilo" respondia-se o mapa é seu, faça o que você achar melhor. Essa resposta ia ao encontro da necessidade de ofertar autonomia aos estudantes para que os mesmos pudessem se despender das convenções cartográficas, que indicam quais os elementos que precisam constar em um mapa, e elaborar suas representações sem as "amarras" conceituais. Segundo Richter (2011), a elaboração desses mapas com mais liberdade em relação à imposição da 
presença dos símbolos cartográficos aparece como possibilidade de expressão de diferentes elementos existentes no cotidiano dos educandos que não são vistos nos mapas tradicionais.

O ambiente de produção dos mapas mentais sempre foi extremamente descontraído porque os estudantes se mostravam muito entusiasmados com a oficina, em algumas escolas apresentou-se até certa competição entre eles. Ao todo foram produzidos 124 mapas, confeccionados por educandos de 14 a 21 anos, porém para a discussão do presente texto analisou-se apenas oito mapas mentais, a escolha se deu porque estes mapas apresentavam uma espacialidade carregada de valores e sentimentos, esses oito exemplares também tinham visão mais ampla e detalhada do lugar, com uma escala geográfica que extrapola o local de moradia, certamente esses jovens tem uma locomobilidade intensa, vivenciam o lugar com mais intensidade e por isso consegue apontar detalhes que os outros não visualizam.

O mapa $A$, apresentado na figura 1, é um demonstrativo de sentimento de pertencimento do educando em relação ao seu lugar, apresentando um amplo conhecimento do espaço vivido. Ele deixa em destaque a sua casa, sendo ela diferenciada das outras residências. Representa também a vizinha e ainda a denomina de "vizinha louca", sendo assim o conflito entre vizinhos também é perceptível nesta representação. $O$ mapa A destaca ainda o "mercado da concorrência" e a "casa da concorrência", cabe pontuar a forma jocosa para demarcar a presença do mesmo tipo de comércio dos seus familiares. Observa-se que o estudante teve o desejo de incluir na representação a casa de pessoas com quem tem um relacionamento de proximidade, sendo de afetos negativos como o da vizinha, ou positivos, como a casa dos/as amigos/as, representando os laços de amizade e sociabilidade do autor. Em relação aos laços afetivos de convívio é de salientar que o mesmo sabe exatamente a localização das casas, enquanto que as residências onde ele não tem nenhum, ou pouco convívio com os seus moradores, não aparecem no mapa.

Já no mapa $B$, apresentado na figura 2, é possível perceber que o estudante também conhece bem o lugar em que vive, apontando os nomes das ruas e detalhando a quantidade de quadras, descrevendo a localização de mercados, padaria, capela mortuária, igreja, escolas, bares, lojas, casa de colegas etc. Ele apresenta uma boa noção de espacialidade do lugar onde mora com uma percepção vertical bem apurada, o que nos leva a crer que a noção de espaço é composta por um conjunto de ideias e imagens que se internalizam no indivíduo através da sua vivência, Ihe permitindo criar representações quase fieis dos lugares nos quais interage diariamente.

Para Rocha (2007, p. 160), cada elemento contido em uma cidade pode ser visto como um signo, que "fala" de forma diferente para cada sujeito: 
Quando se observa uma cidade, uma praça, um monumento, eles gritam uma mensagem inserida num texto não-verbal, à espera de interpretação por parte de quem os observa. Estes elementos constituem o signo. [...] E o signo fala. Mas fala diferente para pessoas diferentes, em momentos diferentes.

Figura 1 - Mapa Mental A

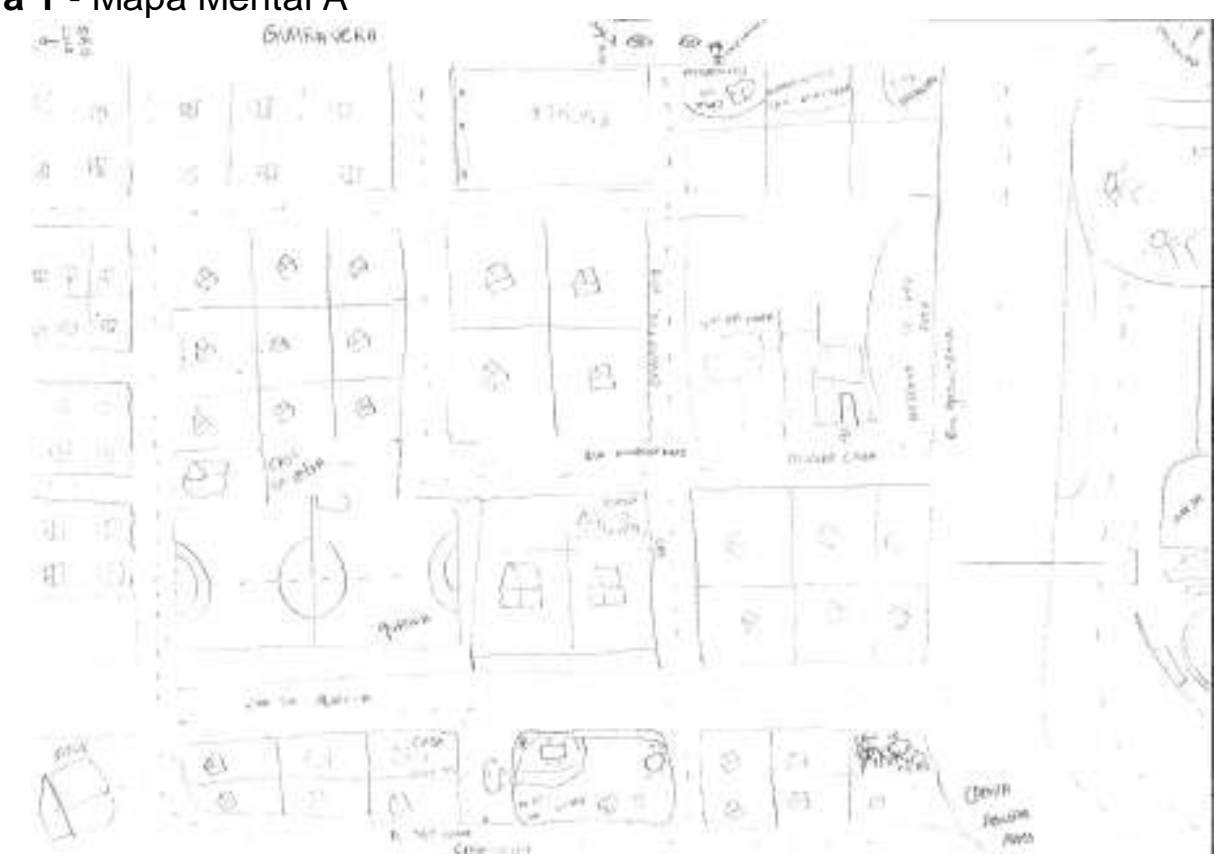

Fonte: Estudantes das escolas estaduais de Ensino Médio dos distritos de Londrina.

Figura 2 - Mapa Mental B

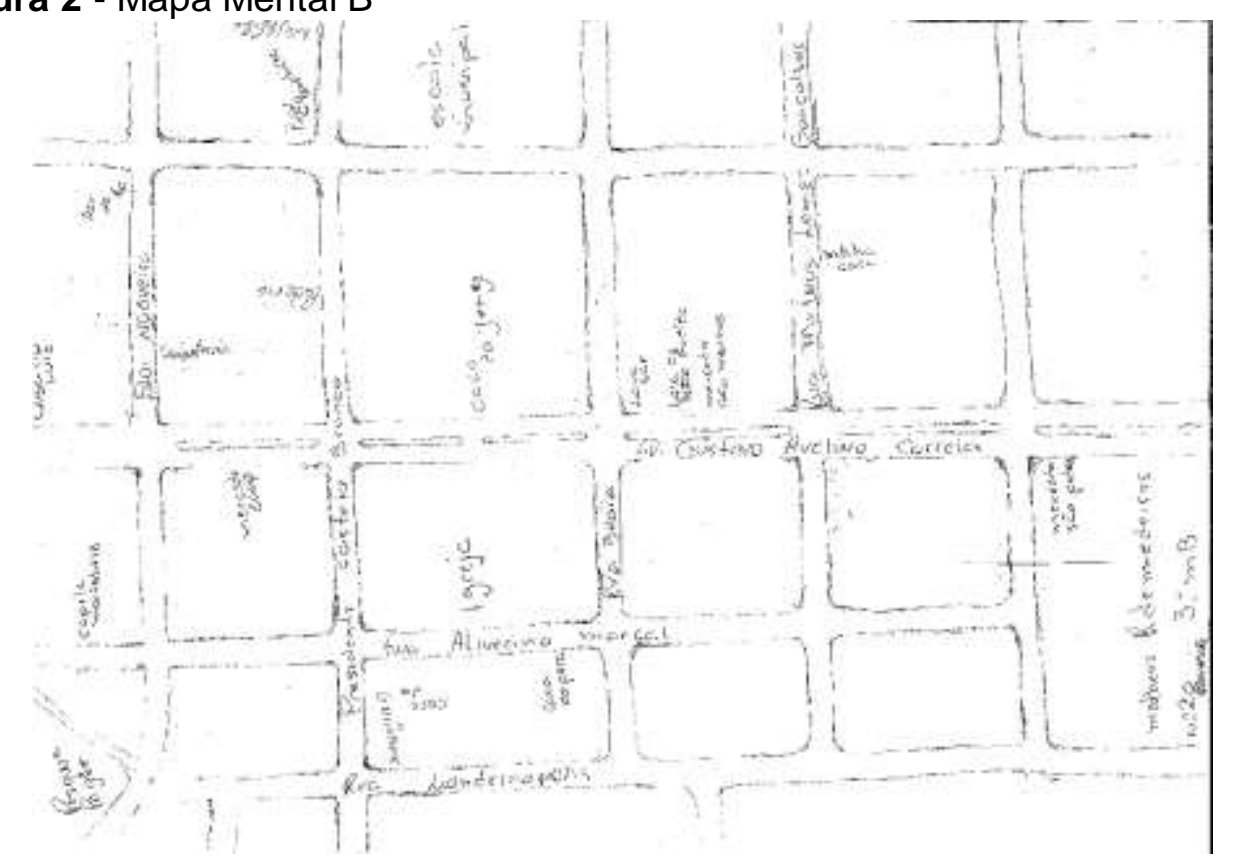

Fonte: Estudantes das escolas estaduais de Ensino Médio dos distritos de Londrina. 
Por isso, podem-se verificar alguns elementos em comum entre vários mapas do mesmo lugar como: igreja, a quadra de futebol e a praça, entretanto todos são desenhados de formas distintas, com muitos ou poucos detalhes e com escalas diferenciadas, conforme os laços de sociabilidade de cada indivíduo.

O mapa $C$, representado na figura 3 , demonstra um conhecimento detalhado do estudante em relação ao seu lugar, parte considerável do distrito em que vive aparece em seu mapa: as ruas, os bairros, as quadras, cemitérios e a casa dos amigos. O que para ele é importante aparece com ênfase no mapa como se pode observar.

Figura 3 - Mapa Mental C

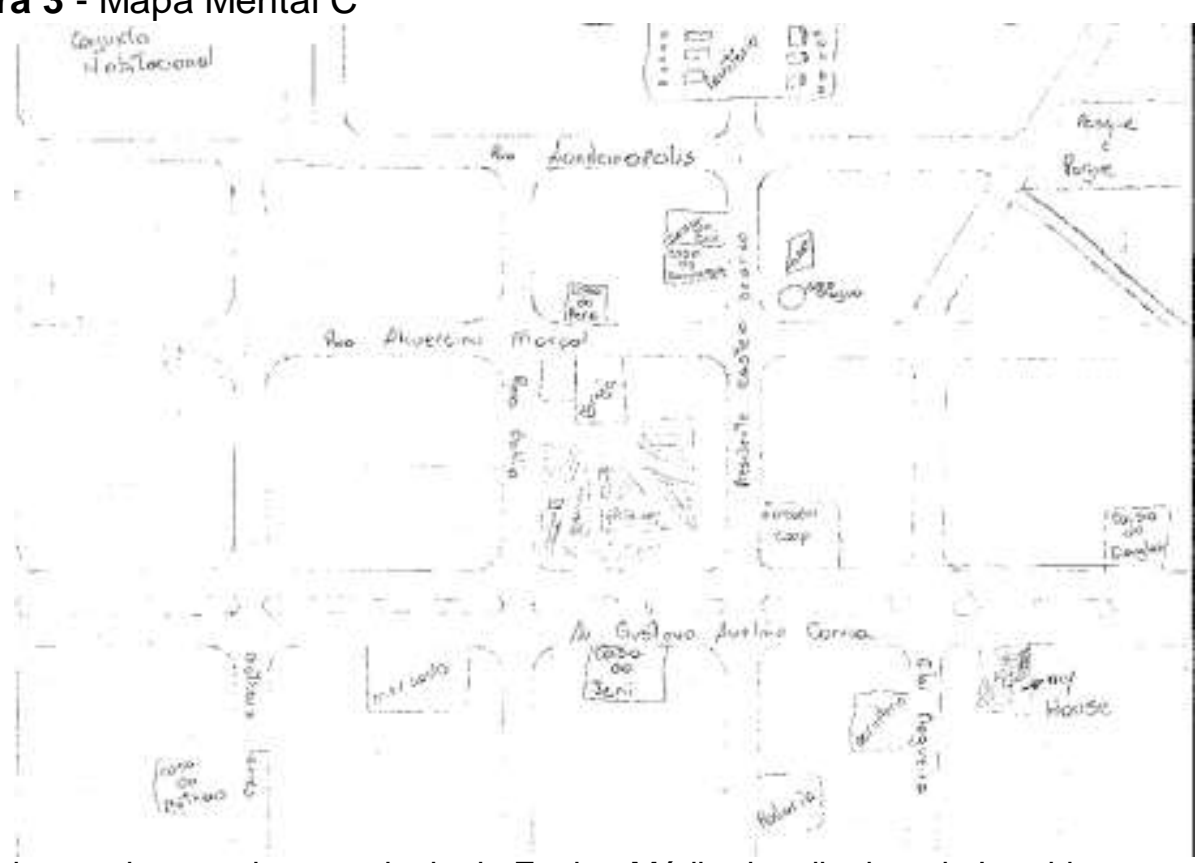

Fonte: Estudantes das escolas estaduais de Ensino Médio dos distritos de Londrina.

O mapa $D$, representado na figura 4, apresenta também uma percepção espacial bem detalhada do espaço vivido, já que o mesmo desenhou as ruas como realmente são com suas curvas e saídas.

Ainda sobre o mapa $D$, pode-se perceber uma relação de pertencimento com o lugar, o adolescente representou pontos importantes no distrito, e também lugares que tem significados para ele, como sua residência, dois campos de futebol, a casa da tia, vizinhas e amigos. Observa-se que dois de seus amigos recebem destaque com os dizeres: "casa do mano", demonstrando que as formas espaciais, muitas vezes, remetem às relações de afetividade e amizade.

Com a observação do espaço vivido, destaca-se que as transformações são diárias, ocorrendo mudanças constantes, que diferenciam o olhar e os sentimentos daqueles que tem tal espaço de vivência, que se transforma em lugar, à medida que se identifica com o 
mesmo. Dessa forma, ocorre o encontro de proximidade e apego do ser humano com o lugar:

As transformações no espaço ocorrem diariamente, surgem locais de referência, que se transformam em pontos de referência à medida que se tornam espaços de identificação e de expressão urbana, ou seja, à medida que esses locais relacionam-se com os humanos pelos sentimentos e vivências (OLIVEIRA, 2006, p. 45).

Figura 4 - Mapa Mental D

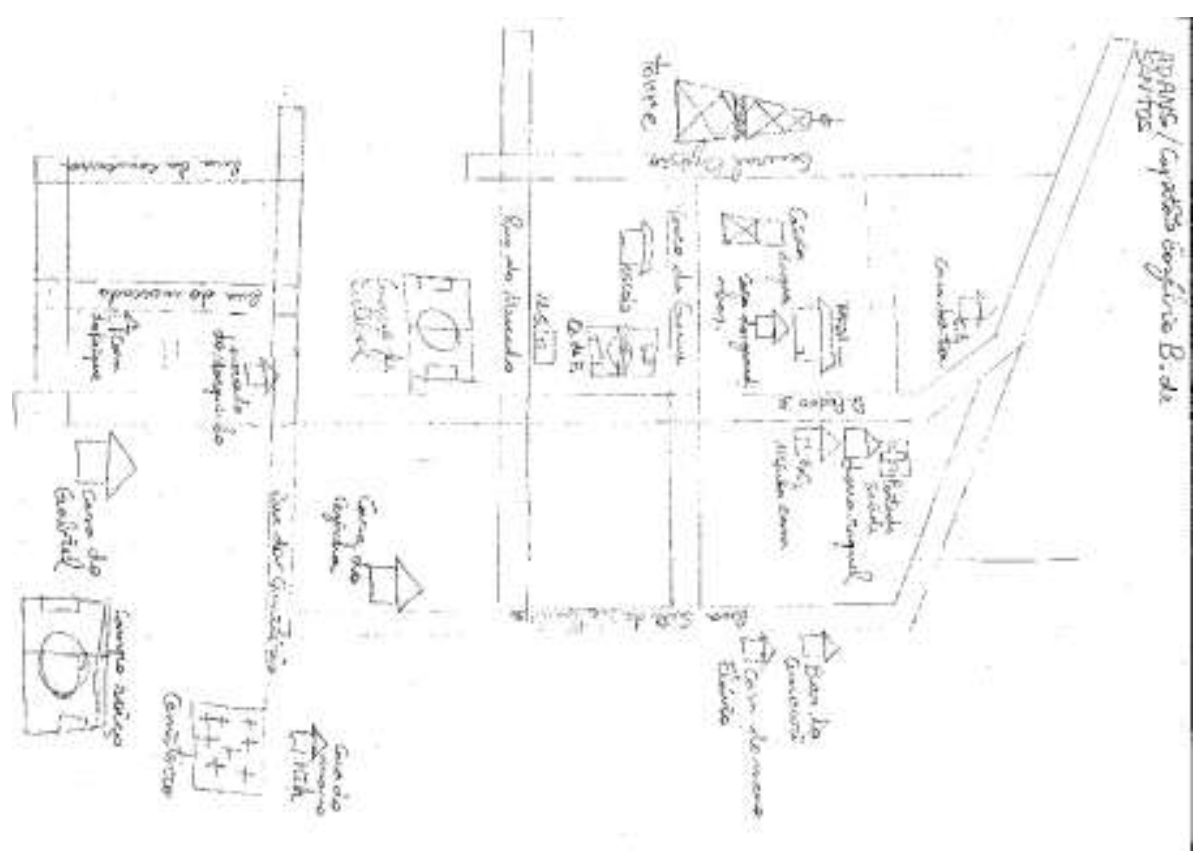

Fonte: Estudantes das escolas estaduais de Ensino Médio dos distritos de Londrina.

O mapa mental $\mathrm{E}$, representado na figura 5, demonstra diversos pontos de referências, sendo eles fundamentais para o aluno que construiu o mapa e também para quem observa e desconhece o lugar, tendo informações significativas para um melhor entendimento e de como se deslocar pelo distrito representado.

Tem-se como pressuposto que os pontos de referência para o estudante são fundamentais e que sua observação é perspicaz, pois é possível verificar neste mapa que o adolescente é um bom observador do espaço vivido. Certamente, faz uso da bicicleta ou caminha até seu colégio. A visão de uma pessoa que utiliza transporte e o de outro que vai á pé para o colégio são completamente distintas, o segundo tem um tempo mais lento para chegar ao colégio e isso possibilita uma percepção espacial mais ampliada.

Os mapas mentais $\mathrm{F}, \mathrm{G}$ e $\mathrm{H}$ representados respectivamente nas figuras 6,7 e 8, apresentam uma relação de afetividade e pertencimento entre os sujeitos e o lugar, pois os estudantes demonstram conhecer e ter uma relação com todos os elementos apresentados por eles. 
Figura 5 - Mapa Mental E
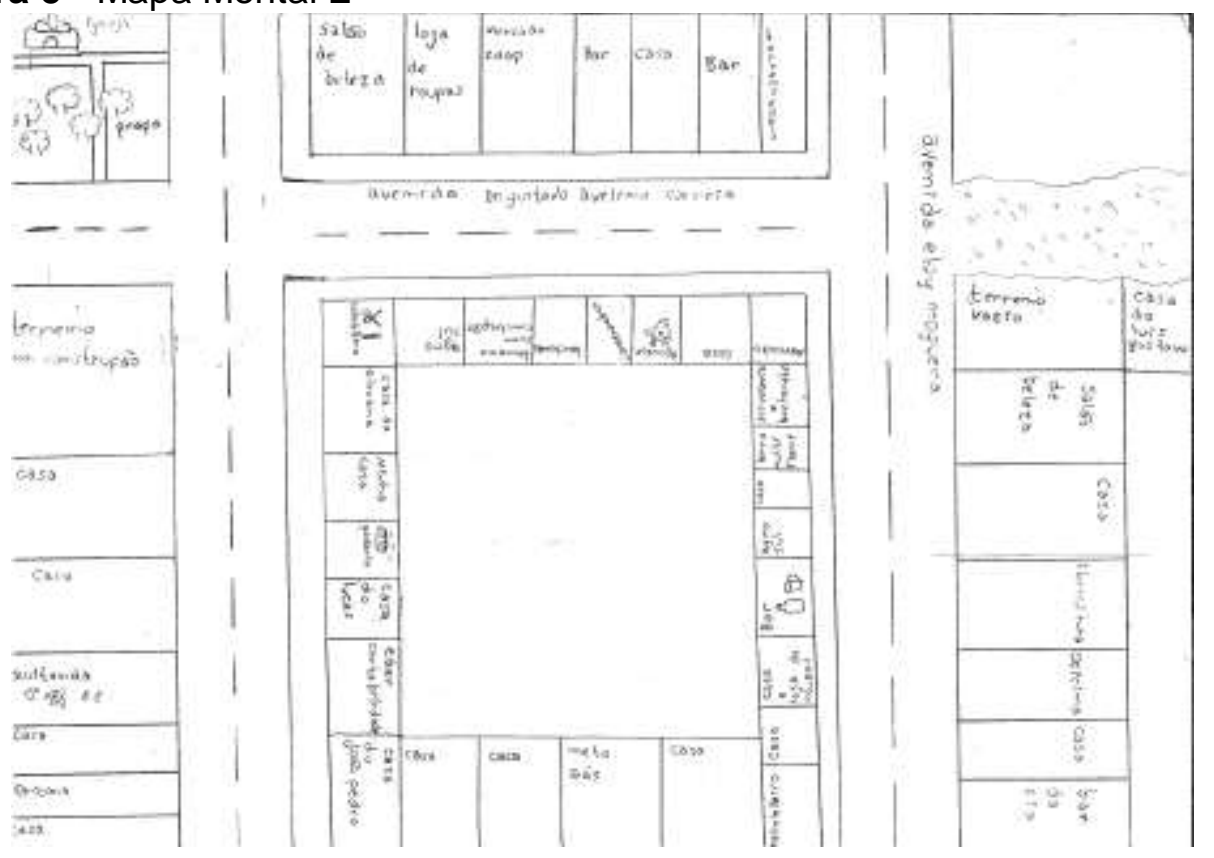

Fonte: Estudantes das escolas estaduais de Ensino Médio dos distritos de Londrina.

Figura 6 - Mapa Mental F

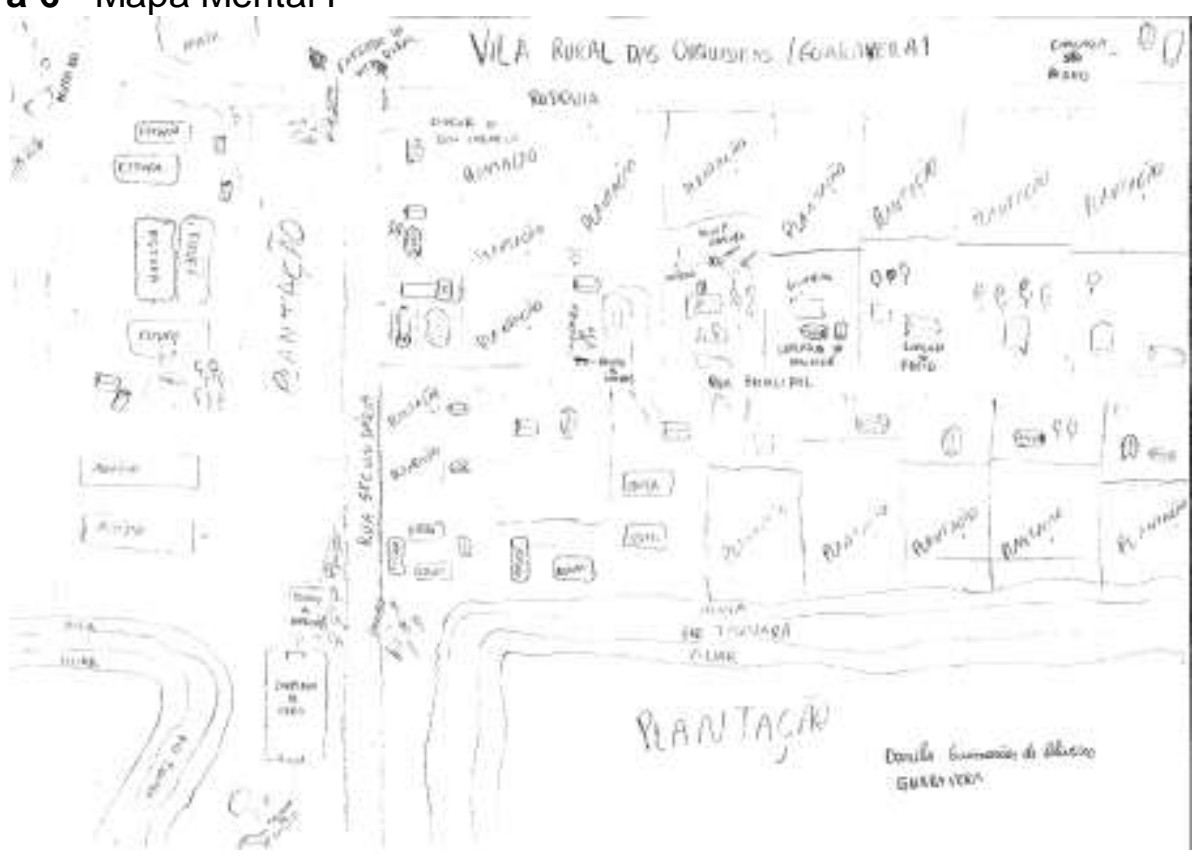

Fonte: Estudantes das escolas estaduais de Ensino Médio dos distritos de Londrina.

Percebe-se que os três jovens demonstraram certo conhecimento da propriedade em que vivem e o seu entorno, com escalas e distribuições do desenho com perspectivas parecidas. Pressupõe-se que os jovens em questão auxiliam seus familiares nos afazeres diários, ou então os acompanham durante o trabalho produtivo, percorrendo toda a 
propriedade. O mapa $\mathrm{F}$ chama atenção quando o aluno desenha o rio que percorre as propriedades e em suas margens a mata ciliar. Esse educando destaca a Vila Rural das Orquídeas e apresenta uma vivência intensa com seu lugar, sabendo sobre diversas estórias. Durante a confecção contou várias, o mesmo conhece as pessoas, as atividades de trabalho produtivo, as festas e as práticas socais, ou seja, ele tem para com a Vila Rural o sentimento de espaço vivido e atribui, ao mesmo, vários significados e valores.

Figura 7 - Mapa Mental G

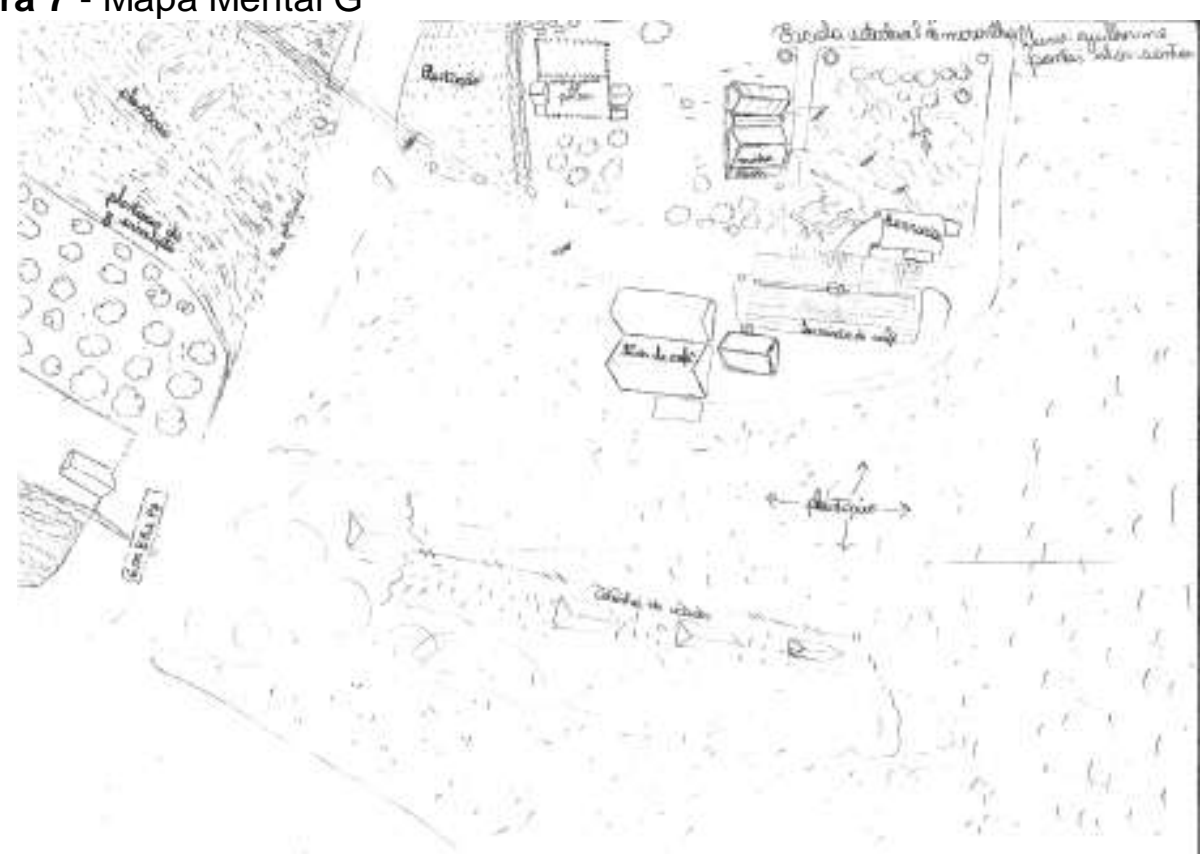

Fonte: Estudantes das escolas estaduais de Ensino Médio dos distritos de Londrina.

Figura 8 - Mapa Mental H

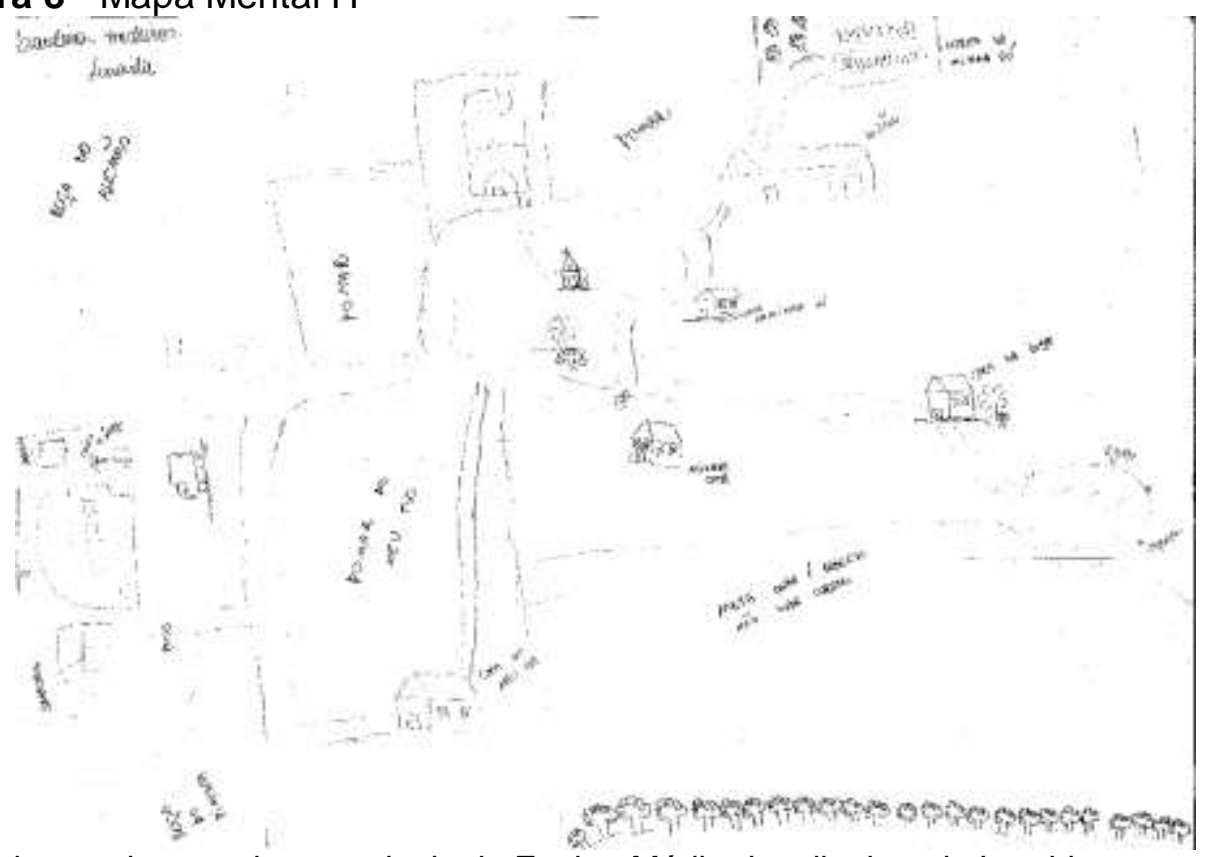

Fonte: Estudantes das escolas estaduais de Ensino Médio dos distritos de Londrina. 
No mapa G é possível perceber que o jovem que o confeccionou possui um raciocínio geográfico considerável, porque ele localiza vários fenômenos no espaço vivido, e os representa de modo que consiga visualizar a produção e organização do espaço que rodeia sua casa. Ele apresenta algumas atividades econômicas como plantio de eucaliptos, criação de porcos e um lugar ao sul da sua residência onde se beneficia o café. A leste da casa há a representação de várias árvores cortadas, talvez isso expresse uma forma de denúncia, demonstrando seu "olhar espacial" para a questão ambiental.

$\mathrm{O}$ mapa $\mathrm{H}$ chama atenção pela sensibilidade ambiental, o jovem apresenta a horta da avó, três pomares de diferentes donos e um espaço onde foram desenhadas várias árvores com os dizeres "mata onde é reserva, não pode cortar". Portanto, certamente é de conhecimento da comunidade que naquele espaço as árvores precisam ser preservadas, neste sentido podemos perceber que os saberes tradicionais da comunidade são transmitidos aos mais novos e assim o processo de reprodução dos costumes, das verdades, dos dizeres e das crenças se mantém vivos. Este estudante conhece a necessidade de manutenção de uma área de preservação em propriedade rural. Esses saberes são de igual importância, de modo a dar continuidade à manutenção da mata ciliar da propriedade que herdarão, o que demonstra também uma relação de respeito pela natureza.

Cabe ressaltar que, mesmo que os mapas apresentem diversos pontos em comum, e que tenham semelhanças, as representações feitas pelos estudantes são subjetivas, observa-se que cada sujeito demonstra, em seu mapa mental, o que mais the chama atenção no dia a dia, o que, para Rocha (2007, p. 161), pode ter diversos significados para o sujeito:

Num mapa mental seu autor registra, via de regra, os elementos do espaço que mais the dizem alguma coisa, com os quais mais se identifica, ou elementos dos quais mais faz uso no seu dia-a-dia ou, ainda, aqueles elementos que mais Ihe chamam a atenção por serem exóticos, ou por seu valor histórico, ou porque tem uma relação de afetividade.

Observa-se que alguns elementos nos mapas se repetiram, todavia não foram representados de forma idêntica, tendo tamanhos, proporções e sentidos diferenciados. A quadra de futebol, por exemplo, para alguns jovens é apenas um ponto de referência, para outros ela está repleta de significados, sendo um ponto de encontro onde se estabelecem relações de amizades.

Entende-se que os oito mapas são de sujeitos que conhecem bem o seu lugar, que percorrem todo o espaço vivido com muita regularidade, representando grande quantidade de detalhes e certa dose de pertencimento e afetividade para com o espaço vivido. Segundo 
Tuan (2013), em diversas vezes o lugar pode ter uma relação direta com a afetividade, sendo que essa afetividade está relacionada com os laços de afeição com os familiares e amigos que ali residem. Isso foi perceptível porque em todos os mapas apresentados neste texto aparecem referências afetivas, seja de amigos ou de familiares.

Tem-se como pressuposto que os mapas mentais têm relação direta com o viver, o sentir e o pensar de uma pessoa e que, por meio de sua representação, o professor pode entender o lugar a esta que pertence. Segundo Rocha (2007, p. 159), os mapas mentais são informações da mente do indivíduo, entretanto eles podem estar atrelados de forma direta ou por informações disponíveis.

Cada mapa mental é portador de informações espaciais armazenadas na mente de um indivíduo, as quais estão de acordo com experiências e percepção de um determinado lugar. Tais experiências podem ter sido adquiridas de forma direta (contato pessoal) ou através dos vários meios de informação disponíveis (rádio, televisão, jornais, romances, filmes, infovias, relato de viagens, entre outros).

Dessa forma, entende-se que o estudante, ao construir o mapa mental, pode levar em consideração um lugar que sonha conhecer, que tenha visto apenas pelos meios de comunicação, site de buscas ou redes sociais. Ferreira (2000) destaca afirma, apoiada em Buttimer, dois elementos fundamentais no entendimento do lugar: o lar e o horizonte de alcance, o primeiro está ligado à segurança e o segundo ao que sonhamos conhecer. Segundo a autora, às vezes desprezamos o primeiro e endeusamos o segundo, devido aos símbolos e apelos da sociedade do consumo que transforma os lugares em mercadoria.

\section{APONTAMENTOS FINAIS}

Primeiramente cabe o registro da satisfação em realizar essa atividade com estudantes de escolas do campo, porque proporcionou às pesquisadoras conhecer um pouco mais a vivência dos educandos, seus sentimentos (medos, tristezas, valores e alegrias), perspectiva de futuro e também as interações e dinâmicas das comunidades rurais e a produção de espacialidades.

Em relação à leitura das espacialidades conclui-se que, nos oito mapas, os educandos apresentam uma visão ampla do espaço vivido, e demonstram uma interação fervilhante com os pares e com o seu espaço de convivência familiar. São jovens mais sociáveis, com locomobilidade intensa e também, com certeza, contam com uma sensibilidade de percepção espacial aguçada.

Durante a confecção dos mapas, as pesquisadoras mantinham um diálogo com os educandos, o que propiciou uma maior aproximação com o cotidiano dos mesmos. Ao 
perguntar o que eram alguns objetos geográficos representados por eles muito jovens contaram sua história de vida, falaram do trabalho produtivo, das festas, das diversões, das tristezas em perceber que o distrito é um lugar abandonado pelo poder público e outras estórias do lugar que nos fizeram perceber como é difícil a vida dos jovens de uma escola do campo.

Por último, entende-se que a presente oficina fez esses jovens pensarem sobre a espacialidade do seu lugar, levando-os a refletir sobre o espaço vivido. Neste sentido o objetivo inicial foi cumprindo e espera-se reproduzir esta oficina mais vezes.

\section{REFERÊNCIAS}

ARCHELA, R. S.; GRATÃO, L. H. B.; TROSTDORF, M. A. S. O lugar dos mapas mentais na representação do lugar. Geografia, Londrina, v. 13, n. 1, p. 127-14, jan./jun. 2004.

FERREIRA. L. F. Acepções recentes do conceito de lugar e sua importância para o mundo contemporâneo. Revista Território, Rio de Janeiro, ano 5, n. 9, p. 65-83, jul./dez. 2000.

LANDIM NETO, F. O.; DIAS, R. H. L. Mapas mentais e a construção de um ensino de geografia significativo: algumas reflexões. Revista Eletrônica Geoaraguaia, Barra do Garças-MT, v. 1, n. 1, p. 1-12, jan./jul. 2011.

OLIVEIRA, N. A. S. A educação ambiental e a percepção fenomenológica, através de mapas mentais. Revista Eletrônica do Mestrado em Educação Ambiental, Rio Grande, v. 16, p. 1-15, 2006.

RICHTER, Denis. O mapa mental no ensino de geografia. São Paulo: Cultura Acadêmica, 2011.

ROCHA, L. B. Mapa mental: forma de comunicação espacial. In: TRINDADE, G. A.; CHIAPETTI, R. J. (Org.). Discutindo geografia: doze razões para se (re)pensar a formação do professor. Ilhéus: Editus, 2007. p. 159-178.

TUAN, Y. F. Espaço e lugar: a perspectiva da experiência. 1930. Londrina: EDUEL, 2013.

Recebido: maio de 2017.

Aceito: outubro de 2017. 